\title{
Acute glycemic and blood lipid response to the ingestion of a candy bar-like protein supplement compared to its candy bar counterpart
}

\author{
Kristin Dugan 1*, Morgan Lewing ${ }^{1}$, Fanny Dufour ${ }^{1}$, Sara Roman ${ }^{1}$, Caleb Woodall', Mallory McAdams ${ }^{1}$, \\ Andrew White', Lem W Taylor ${ }^{1,2}$, Colin D Wilborn ${ }^{1,2}$ \\ From International Society of Sports Nutrition; 7th Annual ISSN Conference and Expo \\ Clearwater Beach, FL, USA. 24-26 June 2010
}

\section{Background}

To meet the growing demand and market for protein supplements, sports nutrition companies and manufacturers have developed protein supplements in several forms, such as RTDs, bars, and powders. Recently, candy bar-like protein supplements have been developed using sugar alcohols instead of sugar to lessen the glycemic response. However, these candy bar-like substitutes usually have a high concentration of total fat, saturated fat, and cholesterol. It is the purpose of this study therefore to determine the acute glycemic and blood lipid response to ingesting a candy bar-like protein supplement compared to its candy bar counterpart.

\section{Methods}

In a crossover design, 5 male and 5 female subjects $(\mathrm{N}=10$, $24 \pm 5.5$ years, $174 \pm 8.3 \mathrm{~cm}, 80 \pm 21.9 \mathrm{~kg}$ ) consumed either a common candy bar (CBR) or a similar carbohydrate conscious protein bar (PBR). Subjects arrived at the lab on a 12 hour fast at 9:00am and had a baseline blood draw. Subjects then consumed either a candy bar (CBR) or a protein bar (PBR) followed by serial blood draws at 15 minutes (15PST), 30 minutes (30PST), 45 minutes (45PST), and 1 hour (1HR) post consumption. Serum samples were analyzed for blood glucose, insulin, and lipid profiles. All data was analyzed utilizing a 2x5 ANOVA. T-tests were used in the case of a significant interaction. A significance value of 0.05 was adopted throughout.

\section{Results}

A significant time effect and a group $\mathrm{x}$ time interaction effect were observed among groups for changes in blood

${ }^{1}$ Human Performance Laboratory, University of Mary Hardin-Baylor, Belton, TX 76513, USA

Full list of author information is available at the end of the article glucose $(\mathrm{p}>0.05)$. Post Hoc analyses revealed blood glucose levels were significantly different at 15PST (CBR: $112.5 \pm 14.1 .6 \mathrm{mg} / \mathrm{dl}$; PBR: $87.5 \pm 9.2 \mathrm{mg} / \mathrm{dl}$ ), indicating a more profound glucose response from the CBR. A significant increase over baseline was observed for triglyceride independent of group and peaking at 1HR ( $\triangle$ CBR: $15 \pm 5 \mathrm{mg} / \mathrm{dl} ; \Delta$ PBR: $23 \pm 6 \mathrm{mg} / \mathrm{dl}$ ). A significant increase over baseline was observed for insulin independent of group and peaking at 15PST ( $\triangle$ CBR: $42 \pm 27 \mathrm{mg} / \mathrm{dl} ; \Delta$ PBR: $25 \pm 11 \mathrm{mg} / \mathrm{dl})$. No significant change was observed in total cholesterol.

\section{Conclusion}

Blood glucose, triglyceride, and insulin all significantly increased in response to CBR and PBR consumption. However, the blood glucose response to the CBR was significantly greater than that of the PBR with sugar alcohol in place of sugar. These findings suggest that the CBR does have a greater effect on blood glucose, but the PBR still had a strong impact on serum triglycerides and insulin.

\section{Author details \\ ${ }^{1}$ Human Performance Laboratory, University of Mary Hardin-Baylor, Belton, TX 76513, USA . ${ }^{2}$ Exercise Biochemistry Laboratory, University of Mary Hardin-Baylor, Belton, TX 76513, USA.}

Published: 15 September 2010

doi:10.1186/1550-2783-7-S1-P16

Cite this article as: Dugan et al:: Acute glycemic and blood lipid response to the ingestion of a candy bar-like protein supplement compared to its candy bar counterpart. Journal of the International Society of Sports Nutrition 2010 7(Suppl 1):P16. 